\title{
Sistemas de manejo de plantas daninhas utilizando o novo herbicida pyroxasulfone visando ao controle químico de gramíneas em soja
}

\author{
Weed managemet systems using the new herbicide pyroxasulfone aiming \\ at grass control in soybeans
}

Felipe Kiyoshi Morota ${ }^{1 *}$, Willian Daróz Matte ${ }^{1}$, Rubem Silvério de Oliveira Junior ${ }^{1}$, Denis Fernando Biffe ${ }^{1}$, Luiz Henrique Morais Franchini ${ }^{1}$, Jamil Constantin ${ }^{1}$

Resumo - Em face do crescente número de problemas de gramíneas com resistência aos herbicidas inibidores da EPSPs e da ACCase, é muito importante avaliar alternativas de manejo com herbicidas de outros mecanismos de ação. $\mathrm{O}$ objetivo deste trabalho foi avaliar sistemas de manejo contendo o novo herbicida pyroxasulfone visando ao controle de capim-pé-de-galinha (Eleusine indica) e capim-amargoso (Digitaria insularis) e a seletividade para a cultura em aplicações antecedendo a semeadura da soja. O delineamento utilizado foi o de blocos ao acaso, com onze tratamentos e quatro repetições. Todos os tratamentos com herbicidas residuais foram aplicados na segunda dessecação, sete dias antes da semeadura da soja. Cada sistema de manejo contou com duas dessecações sequenciais e uma aplicação em pós-emergência da soja. O melhor controle inicial (até 28 dias após a semeadura) de capim-pé-de-galinha foi observado nos tratamentos contendo pyroxasulfone, embora após a terceira aplicação de herbicidas todos os tratamentos tenham proporcionado excelente controle. No caso de capim-amargoso, a terceira aplicação em pós-emergência da cultura não resultou em nenhum incremento de controle e os melhores resultados foram obtidos com tratamentos que continham herbicidas residuais utilizados na segunda aplicação de dessecação, exceto com chlorimuron-ethyl. Os resultados indicam que a utilização de pyroxasulfone associado a outros herbicidas com atividade residual é uma ótima opção para controle simultâneo de capim-pé-de-galinha e de capim-amargoso, sendo tais tratamentos seletivos para a cultura da soja.

Palavras-chave: capim-amargoso, capim-pé-de-galinha, controle residual, seletividade

Abstract - Due to the increasing number of grasses selected for resistance to the EPSPS and ACCase inhibitors, new alternatives with effective and selective herbicides from different mechanisms of action must be developed. This work was carried out to evaluate weed management systems containing the new herbicide pyroxasulfone aiming at controlling goosegrass (Eleusine indica) and sourgrass (Digitaria insularis) in applications immediately prior to soybean sowing. The design used for the randomized blocks, with eleven treatments and four replicates. All residual herbicides were applied at the second burndown application, seven days prior to soybean sowing. In each system, two sequential burndown applications followed by one post-emergence application were sprayed in each treatment. The best level of initial (up 28 days after crop sowing) control of goosegrass was observed with treatments with pyroxasulfone, although after the third herbicide application all systems provided excellent control of this weed. Concerning to sourgrass, the third post-emergence

Recebido: Outubro 16, 2017. Aceito: Junho 19, 2018.

${ }^{1}$ Departamento de Agronomia, Universidade Estadual de Maringá - UEM, Avenida Colombo, 5790, Zona 7, CEP 87020-900, Maringá, PR, Brasil. E-mail: felipe_morota@hotmail.com; willianmatte@hotmail.com; rsojunior@uem.br; biffeagro@hotmail.com; lhfranchini@gmail.com; constantin@teracom.com.br 
application did not provide any weed control improvement and the best results were found where residual herbicides were applied at the second burndown application, except with chlorimuron-ethyl. Associations with pyroxasulfone with other residual herbicides is an excellent option to provide simultaneous control of goosegrass and sourgrass, and those treatments are selective for soybeans. Keywords: sourgrass, goosegrass, residual control, selectivity

\section{Introdução}

O mercado brasileiro de herbicidas tem apresentado algumas mudanças importantes nos últimos anos. As principais mudanças têm sido causadas pela seleção de plantas daninhas com resistência ao glyphosate. Além da buva (Conyza canadensis, C. bonariensis e $C$. sumatrensis) e do caruru palmer (Amaranthus palmeri), as demais espécies que foram selecionadas até o momento incluem quatro espécies de gramíneas (Poaceae): azevém (Lolium multiflorum), capim-amargoso (Digitaria insularis), capim-pé-de-galinha (Eleusine indica) e capim-branco (Chloris elata) (Heap, 2018).

O capim-pé-de-galinha ocorre tanto em cultivos anuais como perenes, infestando também terrenos baldios, jardins e beiras de estradas. Trata-se de uma espécie anual que apresenta sistema radicular bastante desenvolvido, sendo uma das principais plantas daninhas em condições de solos compactados em áreas de plantio direto, tendo suas características de agressividade pronunciadas devido a apresentar fotossíntese pelo ciclo C4. Em solos de baixa fertilidade ou compactados apresenta vantagem sobre muitas outras espécies, sobressaindo seu poder de competição (Kissmann e Groth, 1997). Cada planta é capaz de produzir mais de 120 mil sementes (Takano et al., 2016).

O capim-amargoso é uma espécie perene nativa de regiões tropicais e subtropicais da América, onde é frequentemente encontrado em pastagens, cafezais, pomares e em áreas ruderais como beira de estradas e terrenos baldios (Machado et al., 2008). Nos últimos anos, esta espécie tem sido uma das plantas daninhas mais problemáticas do Brasil, em função da seleção e rápida dispersão de populações resistentes ao glyphosate em diversas regiões do país (López Ovejero et al., 2017).
Com a seleção de espécies de gramíneas com resistência ao glyphosate, a principal alternativa de controle em pós-emergência na cultura da soja passou a ser os herbicidas cujo mecanismo de ação atua na inibição da enzima ACCase (Correia e Durigan, 2009). No entanto, também aumentou consideravelmente a demanda por herbicidas que apresentem controle em pré-emergência de gramíneas e que sejam seletivos para a cultura da soja. São poucos os herbicidas registrados no Brasil para o controle de capim-amargoso (Gemelli et al., 2012), tornando-se assim imprescindível a busca por novas alternativas visando ao controle dessa planta daninha e de outras da mesma família que infestam os cultivos de soja.

O pyroxasulfone (Figura 1) é um herbicida em fase de desenvolvimento no Brasil para uso em diversas culturas. Ele é ativo em pré-emergência e inibe o crescimento de plantas suscetíveis por meio da inibição da biossíntese de ácidos graxos de cadeia longa (VLCFA) (Tanetani et al., 2009). Tanto o mecanismo de ação quanto os prováveis padrões de uso do pyroxasulfone serão semelhantes ao do S-metolachlor (Stahlman et al., 2010).

Quando comparado ao S-metolachlor, o pyroxasulfone apresenta maior controle de Abutilon theophrasti, Kochia scoparia e Polygonum convolvulus (King e Garcia, 2008). Outros estudos indicam que pyroxasulfone oferece excelente controle residual de Lolium perenne ssp. multiflorum (Hulting et al., 2012; Bond et al., 2014), tanto em aplicações antes da semeadura das culturas quanto em aplicações após a colheita, visando à manutenção da entressafra no limpo. Além de opção para manejo de gramíneas, o pyroxasulfone também apresenta espectro de ação em folhas largas. Estudos indicam que este novo herbicida poderá ser usado em programas de manejo de 

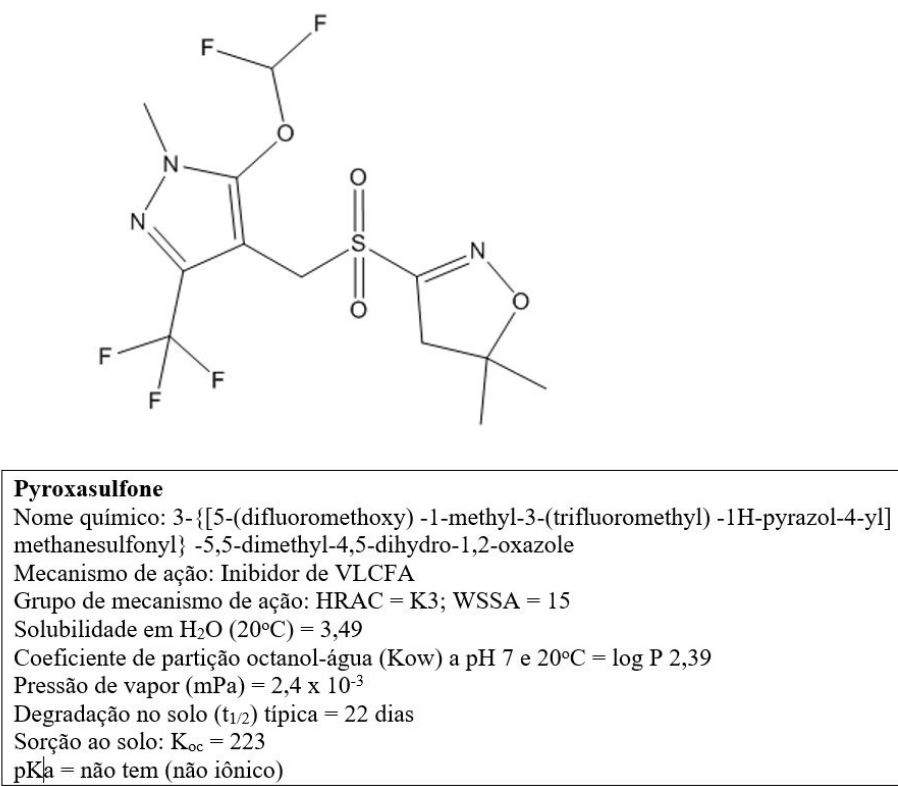

Figura 1. Estrutura química do pyroxasulfone e principais características físico-químicas. Fonte: IUPAC (2017) e EPA (2017).

diversas dicotiledôneas, incluindo espécies do gênero Amaranthus (Harden et al., 2011).

Por se tratar de um herbicida em fase de desenvolvimento, é importante levantar informações sobre sua seletividade e eficácia no controle de plantas daninhas, visando ao correto posicionamento do produto no mercado. Possíveis herbicidas que possam apresentar ação complementar ao pyroxasulfone também devem ser investigados, uma vez que o espectro de controle deve ser o mais amplo possível.

O presente trabalho teve como objetivo avaliar a eficácia e a seletividade de tratamentos contendo o novo herbicida pyroxasulfone, em aplicações antes da semeadura da cultura da soja visando ao controle de capim-pé-de-galinha e capim-amargoso.

\section{Material e métodos}

O ensaio foi instalado no período de $01 / 12 / 2016$ a 13/04/2017. O solo da área experimental apresentava $\mathrm{pH}\left(\mathrm{H}_{2} \mathrm{O}\right) 5,6 ; 21,0 \mathrm{~g} \mathrm{dm}^{-3}$ de $\mathrm{C}$; $24,6 \%$ de areia; $14,6 \%$ de silte e $60,8 \%$ de argila. $\mathrm{Na}$ Figura 2 encontram-se os dados climáticos (temperatura e precipitações) observados durante o período de condução do experimento.

$\mathrm{O}$ delineamento utilizado foi o de blocos ao acaso, com onze tratamentos e quatro repetições, sendo as parcelas compostas por nove linhas de semeadura de soja, em espaçamento de $0,45 \mathrm{~m}$, com comprimento de 5,0 $\mathrm{m}\left(20,25 \mathrm{~m}^{2}\right)$. Considerou-se como área útil para as avaliações e para a colheita apenas as sete linhas centrais de cada parcela, exceto $0,5 \mathrm{~m}$ de cada extremidade $\left(12,6 \mathrm{~m}^{2}\right)$.

$\mathrm{Na}$ Tabela 1 encontram-se os sistemas de manejo com os respectivos herbicidas e doses que foram usados em cada um deles. Em cada tratamento foram realizadas até três aplicações de herbicidas. Para todas as aplicações foi utilizado um pulverizador costal de pressão constante à base de $\mathrm{CO}_{2}$, munido de barra com quatro pontas do tipo leque, modelo Magno 110.02, sob pressão de $2,1 \mathrm{kgf} \mathrm{cm}^{-2}$. Estas condições de aplicação proporcionaram o equivalente a $200 \mathrm{~L} \mathrm{ha}^{-1}$ de calda.

A primeira aplicação dos herbicidas (Aplicação "A") foi realizada no dia 01/12/2016 (07:30-08:20), em pós-emergência das plantas daninhas, na dessecação de manejo que antecedeu a semeadura 


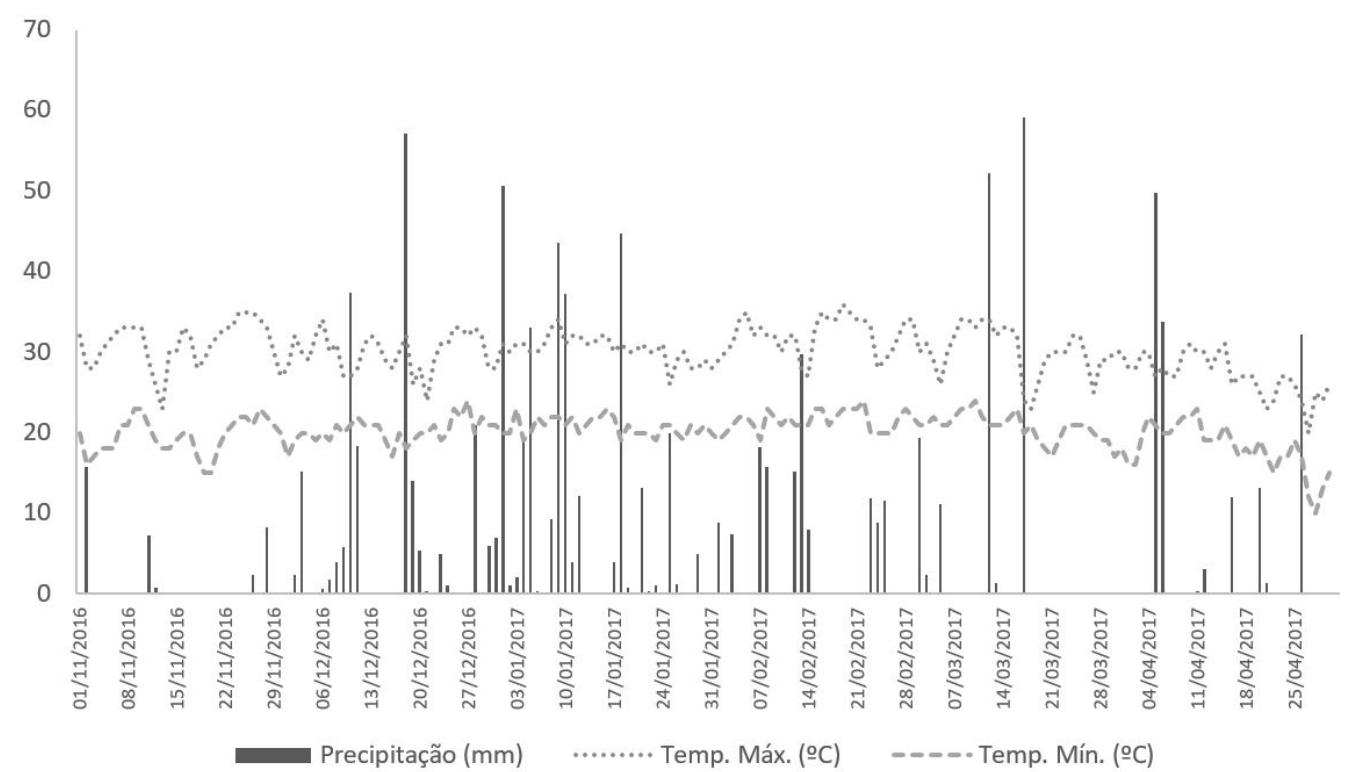

Figura 2. Temperatura máxima, mínima e precipitações diárias observadas durante o período de condução do experimento (2016/2017).

Tabela 1. Tratamentos, respectivas doses e modalidades de aplicações utilizadas no experimento realizado com o herbicida pyroxasulfone aplicado antes da semeadura da cultura da soja. Maringá (PR), 2016/2017.

\begin{tabular}{|c|c|c|}
\hline \multicolumn{2}{|c|}{ Dessecação pré-semeadura } & Pós-emergência \\
\hline Aplicação A $\left(\mathrm{g} \mathrm{ha}^{-1}\right)^{*}$ & Aplicação B ( $\left.\mathrm{g} \mathrm{ha}^{-1}\right)^{*}$ & Aplicação C $\left(\mathrm{g} \mathrm{ha}^{-1}\right)^{*}$ \\
\hline 1. Glyphosate + 2,4-D $(1440+670)$ & Glyphosate (1440) & - \\
\hline 2. Glyphosate + 2,4-D (1440 + 670) & $\begin{array}{l}\text { Glyphosate }+ \text { pyroxasulfone }+ \text { flumioxazin } \\
\qquad(1440+100+60)\end{array}$ & Glyphosate (720) \\
\hline 3. Glyphosate + 2,4-D (1440 + 670) & $\begin{array}{l}\text { Glyphosate }+ \text { pyroxasulfone }+ \text { diclosulam } \\
\qquad(1440+100+29,4)\end{array}$ & Glyphosate (720) \\
\hline 4. Glyphosate + 2,4-D (1440 + 670) & $\begin{array}{l}\text { Glyphosate }+ \text { pyroxasulfone }+ \text { chlorimuron-ethyl } \\
\qquad(1440+100+20)\end{array}$ & Glyphosate (720) \\
\hline 5. Glyphosate + 2,4-D (1440 + 670) & $\begin{array}{c}\text { Glyphosate }+ \text { pyroxasulfone }+ \text { sulfentrazone } \\
\qquad(1440+100+20)\end{array}$ & Glyphosate (720) \\
\hline 6. Glyphosate + 2,4-D $(1440+670)$ & $\begin{array}{l}\text { Glyphosate }+ \text { pyroxasulfone }+ \text { imazethapyr } \\
\qquad(1440+100+100)\end{array}$ & Glyphosate (720) \\
\hline 7. Glyphosate + 2,4-D (1440 + 670) & Glyphosate + diclosulam $(1440+29,4)$ & Glyphosate (720) \\
\hline 8. Glyphosate + 2,4-D $(1440+670)$ & Glyphosate + chlorimuron-ethyl $(1440+20)$ & Glyphosate (720) \\
\hline 9. Glyphosate + 2,4-D (1440 + 670) & Glyphosate + sulfentrazone $(1440+20)$ & Glyphosate (720) \\
\hline 10. Glyphosate $+2,4-\mathrm{D}(1440+670)$ & Glyphosate + imazethapyr $(1440+106)$ & Glyphosate (720) \\
\hline 11. Testemunha capinada & - & - \\
\hline
\end{tabular}

da soja. Esta aplicação foi realizada 30 dias antes da semeadura da cultura da soja e todos os tratamentos com herbicidas (Tratamentos 1 a 10) receberam o mesmo tratamento com glyphosate na dose de $1440 \mathrm{~g}$ e.a. $\mathrm{ha}^{-1}+2,4 \mathrm{D}$ na dose de $670 \mathrm{~g}$ e.a. $\mathrm{ha}^{-1}+$ óleo mineral na dose de 
$0,25 \% \mathrm{v} \mathrm{v}^{-1}$. No momento da aplicação o solo encontrava-se seco, a temperatura do ar era de $28{ }^{\circ} \mathrm{C}$, a umidade relativa do ar estava em $65 \%$, céu claro sem nuvens e ventos de $2,0 \mathrm{~km} \mathrm{~h}^{-1}$. De modo geral, a infestação presente na área era constituída por gramíneas no estádio de até três perfilhos e por folhas largas no estádio de até oito folhas. As touceiras de capim-amargoso resistente ao glyphosate foram removidas manualmente.

A segunda aplicação de herbicidas (Aplicação “B”) foi realizada no dia 07/12/2016 (16:30-18:00), na dessecação de manejo que antecedeu a semeadura da soja. Esta aplicação foi realizada sete dias antes da semeadura da cultura da soja e os tratamentos com herbicidas receberam os herbicidas descritos na Tabela 1. No momento da aplicação o solo encontrava-se úmido, a temperatura do ar era de $30^{\circ} \mathrm{C}$, a umidade relativa do ar estava em $80 \%$, céu nublado e ventos de $1,0 \mathrm{~km} \mathrm{~h}^{-1}$.

Sete dias após a Aplicação "B”, no dia $14 / 12 / 2016$, foi realizada a semeadura direta da soja. Antes da semeadura, as sementes foram tratadas com o inseticida fipronil na dose de $50 \mathrm{~g}$ i.a. por $100 \mathrm{~kg}$ de sementes, e com o fungicida [metalaxil-M + fludioxonil] na dose de [1+2,5] g i.a. por $100 \mathrm{~kg}$ de sementes. A adubação da cultura foi realizada no momento da semeadura, com $180 \mathrm{~kg} \mathrm{ha}^{-1}$ do formulado 02-20-18. Foram distribuídas 18 sementes por metro linear da variedade Dom Mario 6563 IPRO $^{\circledR}$, as quais foram posicionadas a uma profundidade média de $2 \mathrm{~cm}$. A emergência das plântulas ocorreu em 19/12/2016.

A terceira aplicação de herbicidas (Aplicação "C") foi realizada no dia 11/01/2017 (16:00-16:30). Esta aplicação foi realizada 28 dias após a semeadura da soja (DAS) e todos os tratamentos receberam aplicação de glyphosate na dose de $1440 \mathrm{~g} \mathrm{ha}^{-1}$ e.a. + óleo mineral $0,25 \% \mathrm{v} \mathrm{v}^{-1}$. No momento da aplicação o solo encontrava-se úmido, a temperatura do ar era de $26^{\circ} \mathrm{C}$, a umidade relativa do ar estava em $70 \%$, céu nublado e ventos de $0,4 \mathrm{~km} \mathrm{~h}^{-1}$. Nesta ocasião a soja encontrava-se no estádio V4/V5.
As duas principais espécies presentes na área experimental eram capim-pé-de-galinha e capim-amargoso, as quais somavam acima de $90 \%$ da infestação presente na área. Por ocasião da avaliação realizada aos 45 DAS à densidade de infestação destas espécies na testemunha sem herbicida era de 34 e 23 plantas $\mathrm{m}^{-2}$, respectivamente.

Para as avaliações de controle, utilizou-se como referência a infestação da área com lateral de cada parcela, na qual não foi realizada a aplicação de herbicidas. As variáveis avaliadas foram: porcentagem de controle (escala visual, $0-100 \%$, onde $0 \%$ significa ausência de sintomas e $100 \%$ morte total das plantas daninhas) aos 15,22 e 28 DAS e fitointoxicação da cultura, nas mesmas datas, por meio da escala visual de 0 a $100 \%$ (onde $0=$ nenhum sintoma visual de injúria e $100 \%=$ morte de todas as plantas). A avaliação de 28 DAS ocorreu imediatamente antes da Aplicação "C".

Após a Aplicação "C" (28 DAS) também foram realizadas mais duas avaliações de controle e de fitointoxicação da soja, com as mesmas escalas descritas anteriormente. A primeira foi realizada aos 45 DAS (soja no estádio R1) e a segunda na pré-colheita da soja (13/04/2017).

Foram ainda realizadas avaliações da altura das plantas (medida em cm, do solo até a inserção do último trifólio completamente expandido) em oito plantas das duas linhas centrais da área útil das parcelas e de estande da cultura (contagem das plantas emergidas em um metro linear de duas linhas centrais da parcela útil), aos 22 DAS. Estas duas foram avaliações realizadas após as Aplicações "A" e "B", mas antes da Aplicação "C".

Por fim, a produtividade foi estimada por meio da colheita mecanizada no dia 13/04/2017, coletando-se todas as plantas presentes nos $4,0 \mathrm{~m}$ centrais das quatro linhas centrais da área útil das parcelas $\left(7,2 \mathrm{~m}^{2}\right)$, com o uso de uma colhedora de parcelas. Após a colheita, as produções de cada parcela foram pesadas e amostras de cada parcela foram retiradas para determinar o teor de umidade, com o auxílio de um determinador 
automático (determinador de umidade portátil modelo Mini GAC). Posteriormente, todos os dados de produtividade foram corrigidos para $13 \%$ de umidade e transformados para $\mathrm{kg} \mathrm{ha}^{-1}$.

Os dados foram submetidos à análise de variância pelo teste $\mathrm{F}$ e as médias comparadas pelo teste de Tukey, a $5 \%$ de probabilidade.

\section{Resultados e discussão}

Os resultados de controle de capim-pé-de-galinha estão representados na Tabela 2 , em três avaliações realizadas após a Aplicação "B", que antecedeu a semeadura da soja, e antes da Aplicação " $\mathrm{C}$ ". Na primeira avaliação, aos 15 DAS, todos os tratamentos com herbicidas residuais apresentavam $100 \%$ de controle.

Na segunda avaliação, aos 22 DAS, houve uma pequena diferença de controle entre os tratamentos, sendo o menor controle proporcionado pela aplicação de diclosulam (T7) como herbicida residual (93\%), apesar de ainda poder ser considerado um bom nível de controle. Na avaliação que antecedeu a Aplicação "C", aos 28 DAS, observa-se que nos tratamentos nos quais se utilizou somente um herbicida com atividade residual no solo, principalmente chlorimuron-ethyl (T8) e imazethapyr (T10), o controle foi inferior aos tratamentos que continham associações com pyroxasulfone. A utilização de pyroxasulfone associado ao diclosulam (T3) ou ao sulfentrazone (T5) proporcionou $100 \%$ de controle de capim-pé-de-galinha até 28 DAS. Estes resultados indicam que associações contendo pyroxasulfone podem proporcionar excelente controle inicial desta planta daninha.

Nas avaliações feitas após a Aplicação "C", realizadas aos 45 DAS e na pré-colheita (Tabela 2), observou-se $100 \%$ de controle, o que indica que a aplicação de glyphosate em pós-emergência da cultura nos tratamentos 1 ao 10 foi suficiente para garantir controle total de capim-pé-de-galinha até o final do ciclo da soja. O resultado indica que mesmo nos casos onde o controle até 28 DAS não foi $100 \%$ eficiente, a aplicação complementar em pós-emergência resulta em controle efetivo, garantindo o controle de fluxos tardios e a colheita na ausência dessa planta daninha. Eficácia $\geq 95 \%$ no controle de capim-pé-de-galinha por um período de até 60 dias após a semeadura da cultura também foi observada em estudos com pyroxasulfone na cultura do trigo, o que se assemelha em termos de

Tabela 2. Porcentagens de controle de capim-pé-de-galinha em cinco avaliações realizadas após as aplicações "A", "B" e "C" nos tratamentos com herbicidas. Maringá (PR), 2016/2017.

\begin{tabular}{cccccc}
\hline \multirow{2}{*}{ Tratamentos } & \multicolumn{5}{c}{ \% de controle de capim-pé-de-galinha } \\
\cline { 2 - 6 } & 15 DAS & 22 DAS & 28 DAS & 45 DAS & Pré-colheita \\
\hline $\mathbf{0 1}$ & $0,00 \mathrm{~b}$ & $0,00 \mathrm{f}$ & $0,00 \mathrm{~d}$ & $0,00 \mathrm{~b}$ & $0,00 \mathrm{~b}$ \\
$\mathbf{0 2}$ & $100,00 \mathrm{a}$ & $97,00 \mathrm{ab}$ & $95,75 \mathrm{ab}$ & $100,00 \mathrm{a}$ & $100,00 \mathrm{a}$ \\
$\mathbf{0 3}$ & $100,00 \mathrm{a}$ & $100,00 \mathrm{a}$ & $100,00 \mathrm{a}$ & $100,00 \mathrm{a}$ & $100,00 \mathrm{a}$ \\
$\mathbf{0 4}$ & $100,00 \mathrm{a}$ & $97,25 \mathrm{ab}$ & $95,50 \mathrm{abc}$ & $100,00 \mathrm{a}$ & $100,00 \mathrm{a}$ \\
$\mathbf{0 5}$ & $100,00 \mathrm{a}$ & $100,00 \mathrm{a}$ & $100,00 \mathrm{a}$ & $100,00 \mathrm{a}$ & $100,00 \mathrm{a}$ \\
$\mathbf{0 6}$ & $100,00 \mathrm{a}$ & $100,00 \mathrm{a}$ & $96,50 \mathrm{ab}$ & $100,00 \mathrm{a}$ & $100,00 \mathrm{a}$ \\
$\mathbf{0 7}$ & $100,00 \mathrm{a}$ & $93,00 \mathrm{~b}$ & $94,75 \mathrm{abc}$ & $100,00 \mathrm{a}$ & $100,00 \mathrm{a}$ \\
$\mathbf{0 8}$ & $100,00 \mathrm{a}$ & $96,75 \mathrm{ab}$ & $88,75 \mathrm{bc}$ & $100,00 \mathrm{a}$ & $100,00 \mathrm{a}$ \\
$\mathbf{0 9}$ & $100,00 \mathrm{a}$ & $100,00 \mathrm{a}$ & $91,75 \mathrm{abc}$ & $100,00 \mathrm{a}$ & $100,00 \mathrm{a}$ \\
$\mathbf{1 0}$ & $100,00 \mathrm{a}$ & $95,00 \mathrm{ab}$ & $86,75 \mathrm{c}$ & $100,00 \mathrm{a}$ & $100,00 \mathrm{a}$ \\
$\mathbf{1 1}$ & $100,00 \mathrm{a}$ & $100,00 \mathrm{a}$ & $100,00 \mathrm{a}$ & $100,00 \mathrm{a}$ & $100,00 \mathrm{a}$ \\
CV (\%) & - & 2,49 & 4,15 & - & - \\
F & \multicolumn{7}{c}{} & $711,75^{*}$ & $262,17^{*}$ & & \\
DMS & 5,46 & 8,80 & & \\
\hline
\end{tabular}

*Médias na mesma coluna seguidas da mesma letra não diferem entre si, a 5\% de probabilidade pelo teste de Tukey. DAS: Dias após a semeadura), CV(\%): Coeficiente de variação, F: Teste de Fisher e DMS: Diferença mínima sigficativa. 
eficiência ao presente trabalho (Marcussi et al., 2016).

Em relação ao controle de capim-amargoso (Tabela 3), observou-se inicialmente (15 DAS), que a maioria dos tratamentos com herbicidas apresentou controle acima de $95 \%$, o que pode ser considerado excelente. Nas avaliações seguintes (22, 28 e 45 DAS), havia, de modo geral, melhor controle nos tratamentos que continham associações pyroxasulfone em relação aqueles que continham apenas um herbicida com atividade residual, com exceção apenas do tratamento que continha diclosulam (T7).

Também foi possível observar que o controle de capim-amargoso quando comparado ao controle de capim-pé-de-galinha é menor com a utilização dos mesmos tratamentos herbicidas. Dentre os tratamentos que continham associações de residuais, destacou-se aquele com pyroxasulfone e sulfentrazone (T5), que apresentou $100 \%$ de controle até a pré-colheita. A associação de pyroxasulfone com flumioxazin (T2) proporcionou o menor controle final $(90,25 \%)$, semelhante ao tratamento que continha apenas diclosulam como herbicida residual.
Após a aplicação complementar (Aplicação "C") de glyphosate em pós-emergência da soja, não houve praticamente nenhum incremento no controle de capim-amargoso, o que indica que se tratava de uma população resistente ao glyphosate. Os melhores resultados de controle foram obtidos com os tratamentos que continham pyroxasulfone associado com diclosulam, sulfentrazone, chlorimuron-ethyl e imazethapyr, o que reforça a importância da utilização de herbicidas residuais no manejo desta planta daninha, em especial nas áreas onde já houve a seleção de biótipos resistentes ao glyphosate.

A associação de pyroxasulfone com sulfentrazone proporcionou ampliação do espectro de controle de plantas daninhas no caso de infestação de folhas largas como Amaranthus powellii e Abutilon theophrasti, quando comparado com tratamentos contendo os dois herbicidas isolados (Belfry et al., 2015), o que se assemelha aos resultados obtidos no presente trabalho.

Os resultados indicam que o controle obtido com associações de herbicidas residuais que contenham pyroxasulfone resultaram em bom controle de capim-amargoso resistente ao glyphosate até a

Tabela 3. Porcentagens de controle de capim-amargoso em cinco avaliações realizadas após as aplicações "A", "B" e "C" nos tratamentos com herbicidas. Maringá (PR), 2016/2017.

\begin{tabular}{cccccc}
\hline \multirow{2}{*}{ Tratamentos } & \multicolumn{5}{c}{ \% de controle de capim-amargoso } \\
\cline { 2 - 6 } & $\mathbf{1 5} \mathbf{D A S}$ & $\mathbf{2 2} \mathbf{D A S}$ & $\mathbf{2 8} \mathbf{D A S}$ & $\mathbf{4 5} \mathbf{D A S}$ & Pré-colheita \\
\hline $\mathbf{0 1}$ & $0,00 \mathrm{c}$ & $0,00 \mathrm{c}$ & $0,00 \mathrm{e}$ & $0,00 \mathrm{f}$ & $0,00 \mathrm{f}$ \\
$\mathbf{0 2}$ & $97,50 \mathrm{a}$ & $92,75 \mathrm{abc}$ & $90,25 \mathrm{bc}$ & $91,00 \mathrm{bcd}$ & $90,25 \mathrm{bcde}$ \\
$\mathbf{0 3}$ & $95,00 \mathrm{a}$ & $98,50 \mathrm{a}$ & $97,50 \mathrm{ab}$ & $97,75 \mathrm{ab}$ & $97,50 \mathrm{ab}$ \\
$\mathbf{0 4}$ & $99,50 \mathrm{a}$ & $97,00 \mathrm{ab}$ & $95,50 \mathrm{ab}$ & $95,50 \mathrm{abc}$ & $95,50 \mathrm{abc}$ \\
$\mathbf{0 5}$ & $99,75 \mathrm{a}$ & $100,00 \mathrm{a}$ & $100,00 \mathrm{a}$ & $100,00 \mathrm{a}$ & $100,00 \mathrm{a}$ \\
$\mathbf{0 6}$ & $100,00 \mathrm{a}$ & $97,50 \mathrm{a}$ & $95,00 \mathrm{ab}$ & $96,00 \mathrm{ab}$ & $95,00 \mathrm{ab}$ \\
$\mathbf{0 7}$ & $99,50 \mathrm{a}$ & $94,00 \mathrm{ab}$ & $90,50 \mathrm{bc}$ & $92,25 \mathrm{abc}$ & $90,50 \mathrm{abcd}$ \\
$\mathbf{0 8}$ & $85,00 \mathrm{~b}$ & $94,25 \mathrm{~d}$ & $80,50 \mathrm{~d}$ & $80,00 \mathrm{e}$ & $80,50 \mathrm{e}$ \\
$\mathbf{0 9}$ & $96,25 \mathrm{a}$ & $89,50 \mathrm{bcd}$ & $84,75 \mathrm{~cd}$ & $86,75 \mathrm{cde}$ & $84,75 \mathrm{cde}$ \\
$\mathbf{1 0}$ & $97,50 \mathrm{a}$ & $86,25 \mathrm{~cd}$ & $84,25 \mathrm{~cd}$ & $83,00 \mathrm{de}$ & $84,25 \mathrm{de}$ \\
$\mathbf{1 1}$ & $100,00 \mathrm{a}$ & $100,00 \mathrm{a}$ & $100,00 \mathrm{a}$ & $100,00 \mathrm{a}$ & $100,00 \mathrm{a}$ \\
$\mathbf{C V}(\%)$ & 4,11 & 3,59 & 4,39 & 4,30 & 5,23 \\
$\mathbf{F}$ & $266,31^{*}$ & $354,11^{*}$ & $241,31^{*}$ & $251,00 *$ & $172,46 *$ \\
DMS & 8,91 & 7,54 & 9,00 & 8,87 & 10,65 \\
\hline
\end{tabular}

*Médias na mesma coluna seguidas da mesma letra não diferem entre si, a 5\% de probabilidade pelo teste de Tukey. DAS: Dias após a semeadura), CV(\%): Coeficiente de variação, F: Teste de Fisher e DMS: Diferença mínima sigficativa. 
pré-colheita, tratando-se de uma boa opção de manejo desta planta daninha. Os tratamentos que continham somente um herbicida com atividade residual foram inferiores se comparados com a associação destes com o pyroxasulfone. De acordo com Parreira et al. (2010), a associação de herbicidas residuais ao glyphosate, além de impedir a emergência das plantas daninhas por um período, ainda pode melhorar a eficácia do glyphosate sobre plantas de difícil controle.

No trabalho de pesquisa conduzido por Marcussi et al. (2016), observou-se eficácia de pelo menos $95 \%$ de controle de capim-amargoso por um período de 60 dias após a semeadura da cultura com a utilização de pyroxasulfone + flumioxazin, o que se assemelha em termos de eficiência aos resultados obtidos no presente trabalho. Curvas de dose-resposta mostram que o pyroxasulfone em doses de 200 a 300 g i.a. $\mathrm{ha}^{-1}$ promove excelente controle da maioria das gramíneas e de algumas folhas largas na cultura do milho por pelo menos quatro semanas, dentro do ciclo da cultura, em solos com até 3\% de matéria orgânica (Knezevic et al., 2009). Outros resultados de controle adequado de gramíneas são também relatados por Currie e Regehr (2005) e por Olson et al. (2011).

Em relação à seletividade dos tratamentos para a cultura da soja, não foi observado nenhum sintoma perceptível de injúrias na parte aérea das plantas, nas avaliações realizadas (dados não apresentados). As avaliações relacionadas à altura das plantas e ao estande da soja também não indicaram nenhum efeito tóxico dos tratamentos sobre estas variáveis-resposta (Tabela 4). De forma semelhante ao que foi observado no presente trabalho, Stephenson et al. (2017) concluíram que, independentemente da época, pré-emergência ou pós-emergência ou das doses utilizadas (variando entre 60 e $300 \mathrm{~g} \mathrm{ha}^{-1}$ ), este herbicida pode ser aplicado na cultura da soja sem causar redução no crescimento das plantas ou no rendimento.

No que concerne ao efeito dos tratamentos sobre a produtividade de grãos (Tabela 4), os tratamentos com aplicação de pyroxasulfone associado a outros herbicidas com atividade

Tabela 4. Efeito dos tratamentos herbicidas sobre a altura, estande e produtividade de grãos da soja no experimento com pyroxasulfone aplicado antes da semeadura da cultura. Maringá (PR), $2016 / 2017$.

\begin{tabular}{|c|c|c|c|}
\hline Tratamentos & Altura (cm) ${ }^{1 /}$ & Estande $\left(\text { plantas } \mathbf{m}^{-1}\right)^{1 /}$ & $\begin{array}{c}\text { Produtividade de grãos } \\
\left(\mathrm{kg} \mathrm{ha}^{-1}\right)\end{array}$ \\
\hline 01 & $13,66 \mathrm{a}$ & $12,88 \mathrm{a}$ & $309,72 \mathrm{c}$ \\
\hline 02 & $13,60 \mathrm{a}$ & $13,38 \mathrm{a}$ & $2889,75 \mathrm{ab}$ \\
\hline 03 & $13,25 \mathrm{a}$ & $13,38 \mathrm{a}$ & $2765,57 \mathrm{ab}$ \\
\hline 04 & $13,69 \mathrm{a}$ & $14,25 \mathrm{a}$ & $2638,91 \mathrm{ab}$ \\
\hline 05 & $13,85 \mathrm{a}$ & $11,38 \mathrm{a}$ & $2825,69 \mathrm{ab}$ \\
\hline 06 & 14,63 a & $12,13 \mathrm{a}$ & $2849,70 \mathrm{ab}$ \\
\hline 07 & $13,81 \mathrm{a}$ & $12,63 \mathrm{a}$ & $2656,96 \mathrm{ab}$ \\
\hline 08 & $14,76 \mathrm{a}$ & $14,88 \mathrm{a}$ & $2559,82 \mathrm{~b}$ \\
\hline 09 & 12,66 a & $13,88 \mathrm{a}$ & $2595,03 \mathrm{~b}$ \\
\hline 10 & 15,88 a & 13,13 a & $2543,35 \mathrm{~b}$ \\
\hline 11 & $14,97 \mathrm{a}$ & 13,13 a & $3005,40 \mathrm{a}$ \\
\hline CV $(\%)$ & 14,56 & 14,44 & 6,20 \\
\hline F & $0,78^{\text {ns }}$ & $1,10^{\text {ns }}$ & $91,61 *$ \\
\hline DMS & 5,04 & 4,71 & 383,14 \\
\hline
\end{tabular}

1/ Avaliação realizada aos 22 DAS; *Médias na mesma coluna seguidas da mesma letra não diferem entre si, a 5\% de probabilidade pelo teste de Tukey. ns: Não significativo, CV(\%): Coeficiente de variação, F: Teste de Fisher e DMS: Diferença mínima significativa. 
residual no solo apresentaram melhores resultados quando comparados aos tratamentos que continham somente um herbicida residual, com exceção do tratamento com diclosulam (T7), que apresentou produtividade, assim como controle de capim-amarogoso, semelhante aos tratamentos com dois herbicidas residuais. As diferenças de produtividade entre os tratamentos com associações contendo pyroxasulfone e os tratamentos com somente um herbicida de atividade residual no solo (Tabela 4), estão possivelmente relacionadas à falta de controle em alto nível desta planta daninha na cultura, resultando em menor produtividade, quando comparado com os melhores tratamentos e com a testemunha capinada.

\section{Conclusões}

Os tratamentos que resultaram em melhor controle inicial de capim-pé-de-galinha foram os que continham pyroxasulfone, com destaque para as associações deste herbicida com diclosulam e sulfentrazone, mas todos os sistemas de manejo apresentaram controle total desta planta daninha após a aplicação em pós-emergência da soja.

No controle inicial de capim-amargoso observa-se um nível satisfatório para a maioria dos tratamentos com herbicidas, exceto com chlorimuron-ethyl. Após a aplicação "C" não houve nenhum incremento de controle desta planta daninha. Os resultados indicam que a utilização de pyroxasulfone associado a outros herbicidas de atividade residual é uma ótima opção para controle simultâneo de capim-pé-de-galinha e de capim-amargoso, sendo tais tratamentos seletivos para a cultura da soja. Os melhores resultados de produtividade foram obtidos nos tratamentos que continham associações contendo pyroxasulfone.

\section{Referências}

Belfry, K.D.; McNaughton, K.E.; Sikkema, P.H. Weed control in soybean using pyroxasulfone and sulfentrazone. Canadian Journal of Plant
Science, v.95, n.6, p.1199-1204, 2015. http:// dx.doi.org/10.4141/cjps-2015-114.

Bond, J.A.; Eubank, T.W.; Bond, R.C.; Golden, B.R.; Edwards, H.M. Glyphosate-resistant italian ryegrass (Lolium perenne ssp. multiflorum) control with fall-applied residual herbicides. Weed Technology, v.28, n.2, p.361-370, 2014. http:// dx.doi.org/10.1614/WT-D-13-00149.1.

Correia, N.M.; Durigan, J.C. Manejo químico de plantas adultas de Digitaria insularis (L.) Fedde com glyphosate isolado e em mistura com chlorimuronethyl ou quizalofop-p-tefuril em área de plantio direto. Bragantia, v.68, n.3, p.689-697, 2009. http://dx.doi.org/10.1590/S000687052009000300016 .

Currie, R.S.; Regehr, D.L. Comparisons of KIH485 and s-metolachlor for weed control in corn. In: North Central Weed Science Society Meeting, 60., 2005, Kansas City. Proceedings... Kansas City: NCWSS, 2005. p.84.

EPA - U.S. Environmental Protection Agency. Pyroxasulfone. North Carolina, 2017. Disponível em: <https://comptox.epa.gov/dashboard/dsstoxdb/ results? search=DTXSID4058104>. Acesso em: 05 out. 2017.

Gemelli, A.; Oliveira Junior, R.S.; Constantin, J.; Braz, G.B.P.; Jumes, T.M.C.; Oliveira Neto, A.M.; et al. Aspectos da biologia de Digitaria insularis resistente ao glyphosate e implicações para o seu controle. Revista Brasileira de Herbicidas, v.11, n.,2, p.231-240, 2012. http:// dx.doi.org/10.7824/rbh.v11i2.186.

Harden, J.; Thomas, W.; Bond, R.C.; Bowe, S.R.; Honda, H.; Yamaji, Y. Residual control of Amaranthus and other key weeds in corn and soybean with pyroxasulfone. In: Southern Weed Science Society Meeting, 64., 2011, San Juan. Proceedings... San Juan: SWSS, 2011. p.49.

Heap, I. The International Survey of Herbicide Resistant Weeds. 2018. Disponível em: $<$ http:// www.weedscience.org> . Acesso em: 19 mar. 2018. 
Hulting, A.G.; Dauer, J.T.; Hinds-Cook, B.; Curtis, D.; Koepke-Hill, R.M.; Mallory-Smith, C. Management of italian ryegrass (Lolium perenne ssp. multiflorum) in western Oregon with preemergence applications of pyroxasulfone in winter wheat. Weed Technology, v.26, n.02, p.230-235, 2012. http://dx.doi.org/10.1614/WTD-11-00059.1.

IUPAC - International Union of Pure and Applied Chemistry. Global Availability of Information on Agrochemicals. THE PPDB Pesticide Properties Database. 2017. Disponível em: $<$ http://sitem. herts.ac.uk/aeru/iupac/Reports/1367.htm>.Acesso em: 5 out. 2017.

King, S.R.; Garcia, J.O. Annual broadleaf control with KIH-485 in glyphosate-resistant furrow-irrigated corn. Weed Technology, v.22, n.3, p.420-424, 2008. http://dx.doi.org/10.1614/ WT-07-169.1.

Kissmann, K.G.; Groth, D. Plantas infestantes e nocivas. Tomo I. 2.ed. São Paulo: BASF, 1997. $825 \mathrm{p}$.

Knezevic, S.Z.; Datta, A.; Scott, J.; Porpiglia, P.J. Dose-response curves of KIH-485 for preemergence weed control in corn. Weed Technology, v.23, n.1, p.34-39, 2009. http://dx.doi.org/10.1614/ WT-08-097.1.

Lopez Ovejero, R.F.; Takano, H.K.; Nicolai, M.; Ferreira, A.; Melo, M.S.C.; Cavenaghi, A.L.; et al. Frequency and dispersal of glyphosate-resistant sourgrass (Digitaria insularis) populations across Brazilian agricultural production areas. Weed Science, v.65, n.2, p.285-294, 2017. http://dx.doi. org/10.1017/wsc.2016.31.

Machado, A.F.L.; Meira, R.M.S.; Ferreira, L.R.; Ferreira, F.A.; Tuffi Santos, L.D.; Fialho, C.M.T.; Machado, M.S. Caracterização anatômica de folha, colmo e rizoma de Digitaria insularis. (L.) Fedde. Planta Daninha, v.26, n.1, p.1-8, 2008. http:// dx.doi.org/10.1590/S0100-83582008000100001.
Marcussi, S.A.; Prates, E.C.N.; Isabel, J.B.; Mendes, C.R.L.G.; Squassoni, V.L.; Velho, G.F. Eficácia do herbicida pyroxasulfone no controle de plantas daninhas na cultura do trigo no sistema de plantio direto. In: Congresso Brasileiro da Ciência das Plantas Daninhas, 30., 2016, Curitiba. Anais... Curitiba: SBCPD, 2016. p.285.

Olson, B.L.S.; Zollinger, R.K.; Thompson, C.R.; Peterson, D.E.; Jenks, B.; Moechnig, M.; Stahlman, P.W. Pyroxasulfone with and without sulfentrazone in sunflower (Helianthus annuus). Weed Technology, v.25, n.2, p.217-221, 2011. http://dx.doi.org/10.1614/WT-D-10-00089.1.

Parreira, M.C.; Espanhol, M.; Duarte, D.J.; Correia, N.M. Manejo químico de Digitaria insularis em área de plantio direto. Agrária, v.5, n.1, p.13-17, 2010. http://dx.doi.org/10.5039/agraria.v5i1a481.

Stahlman, P.W.; Olson, B.L.S.; Thompson, C.R.; Zollinger, R.K. Pyroxasulfone (KIH-485) for weed control in sunflower. In: Australian Summer Grains Conference, 1., 2010, Ashmore. Proceedings... Ashmore: ASGC, 2010. p.1-7.

Stephenson, D.O.; Blouin, D.C.; Griffin, J.L.; Landry, R.L.; Woolam, B.C.; Hardwick, J.M. Effect of pyroxasulfone application timing and rate on soybean. Weed Technology, v.31, n.2, p.202-206, 2017. http://dx.doi.org/10.1017/ wet.2016.25.

Takano, H.K.; Oliveira Junior, R.S.; Constantin, J.; Braz, G.B.P.; Padovese, J.C. Growth, development and seed production of goosegrass. Planta Daninha, v.34, n.2, p.249-257, 2016. http:// dx.doi.org/10.1590/S0100-83582016340200006.

Tanetani, Y.; Kaku, K.; Kawai, K.; Fujioka, T.; Shimizu, T. Action mechanism of a novel herbicide, pyroxasulfone. Pesticide Biochemistry and Physiology, v.95, n.1, p.47-55, 2009. http:// dx.doi.org/10.1016/j.pestbp.2009.06.003. 